\title{
LACAN, DELEUZE E GUATTARI: ESCRITAS QUE SE FALAM
}

\author{
Analice de Lima Palombini \\ Universidade Federal do Rio Grande do Sul, Porto Alegre, Brasil
}

RESUMO: O presente artigo busca estabelecer as balizas para um trabalho de aproximação entre o pensamento de Lacan e o de Deleuze-Guattari, acompanhando as reverberações do que escrevem Deleuze e Guattari no texto lacaniano, e vice-versa, como escritas que se falam. A pesquisa considera que o debate mantido entre esses autores - mesmo quando não explicitado - marcou de forma decisiva as suas produções, dando mostras da efetividade de uma interlocução que, ao pôr em causa suas diferenças, fez-se produtora de movimentos e transformações. Valese, nesse sentido, como método de pesquisa, da noção de amizade, tal como formulada por Foucault e Derrida.

PALAVRAS-CHAVE: Lacan; Deleuze e Guatarri; Psicanálise; Amizade

\section{LACAN, DELEUZE AND GUATTARI: WRITINGS THAT SPEAK TO ONE ANOTHER}

ABSTRACT: Examining the conceptual elaborations of Jacques Lacan on the one hand and of either Gilles Deleuze or Gilles Deleuze and Félix Guattari on the other, through the reverberations upon Lacan of that which Deleuze and Guattari write and vice-versa we hear writings that speak to one another. Even if not always explicit, this conversation has marked the productions of these authors productions in a decisive manner, bespeaking the effectiveness of a dialogue that engenders movements and transformations as it brings its differences into play.

KEYWORDS: Lacan; Deleuze And Guattari; Psychoanalysis; Friendship

O texto que aqui se apresenta é um desdobramento conceitual do percurso de pesquisa que resultou em minha tese de doutorado defendida junto ao Programa de Pós-Graduação em Saúde Coletiva do Instituto de Medicina Social da Universidade Estadual do Rio de Janeiro. Referida ao contexto da reforma psiquiátrica, que toma a cidade, e não mais o asilo, como o espaço em que a loucura requer ser acompanhada, a tese interpela diferentes vertentes da clínica quanto às ferramentas de que dispõem para a incorporação do espaço público ao seu fazer, através de objetos e relações, tanto simbólicos como materiais, sem fazer uso de uma relação de domínio à parte que implique em segregação com respeito à sociedade comum. Com respeito às três concepções de clínica então investigadas - referendadas, respectivamente, em Lacan, em Winnicott, em Deleuze-Guattari -, interessou-me dar seguimento ao trabalho de aproximação entre o pensamento de Lacan e o de DeleuzeGuattari, instigada pelo que se observa como mútuo e franco desconhecimento a afetar as relações entre os muitos profissionais que, referenciados ao pensamento de Lacan ou ao de Deleuze e Guattari, ocupam-se da clínica no campo da atenção psicossocial.

Muitos dirão que este é um tema ultrapassado. Para boa parte dos psicanalistas, O Anti-Édipo, clímax da interlocução de Deleuze e Guattari (1976) com a psicanálise, é um texto datado, próprio à atmosfera instaurada pelos acontecimentos de maio de 68. Nele,
Deleuze e Guattari criticam tanto a concepção de inconsciente da psicanálise, por não levar em conta as determinações políticas do desejo, como também as limitações da teoria marxista por ignorar o desejo como produtor de realidade (Warat, 1992).

OAnti-Édipo foi como um furacão quando se publicou, em 1972, pondo em desordem as teorias e suas disciplinas para perturbar os prestígios da psicanálise. Etnologia, política, linguística, economia, literatura, artes... são muitos os campos do saber de que o livro faz um uso livre e inventivo, em favor da derrocada do Édipo. (Gandillac, 1972/2005). Era a peste para a psicanálise. Mas a potência crítica desse livro escrito a quatro mãos viu-se enfraquecida, na medida em que o Édipo mesmo foi perdendo força como lei reguladora do social - perda que é ainda motivo de lamentação de psicanalistas nostálgicos do pai. O furacão virou brisa leve para uma psicanálise que, mal ou bem, segue de pé. Então, por que revolver esse assunto?

Ora, não é a polêmica o foco com que intentamos pôr em diálogo o que escreve e profere Lacan e o que escrevem Deleuze e Guattari. Mais do que o assinalamento de oposições, o que nos move é a aposta na efetividade de uma interlocução que, ao pôr em causa suas diferenças, é produtora de movimentos e transformações positivas.

Deleuze et la psychanalyse, de Monique DavidMénard (2005), é uma das raras publicações que, em 
tempos recentes, trataram de abordar essa interlocução. Nele se lê que o estrondoso sucesso que obteve o lançamento de $O$ Anti-Édipo marca, ao mesmo tempo, o início de um longo mal-entendido, pois, de um lado, os filósofos de inspiração deleuziana tomaram $O$ AntiÉdipo como manifestação do fim da relação de Deleuze e Guattari com a prática freudiana, enquanto que, de outro, os psicanalistas, em especial na França, chocados pelo ataque virulento do livro à psicanálise, pararam de ler Deleuze... (o livro de David-Ménard não se detém nas referências a Guattari).

Parece ser verdade que a recomendação de Lacan no interior da Escola Freudiana de Paris, quando se publica $O$ Anti-Édipo, é de não comentá-lo, não alimentar a polêmica, ignorá-lo. (Rolnik, 2006). Mas, se a recomendação é tomada ao pé da letra pelos seus seguidores, certamente não o é pelo próprio Lacan. É Deleuze (1996) quem conta que, alguns meses após a publicação do livro, Lacan o chamou ao seu consultório, onde lhe confidenciou sua insatisfação com seus discípulos, os mais próximos, e disse-lhe que precisava de gente como ele. Lacan nunca fez qualquer menção explícita ao Anti-Édipo em seus seminários e escritos, mas os reposicionamentos e torções por que passa sua teoria dão mostras de uma particular atenção aos temas que nele são debatidos, sem que isso signifique uma ruptura com suas elaborações anteriores, mas antes um relançamento, em espiral, de suas questões. Assim, por exemplo, no seminário de 1972-73 (Mais, ainda), a ênfase do ensino de Lacan (1985) irá recair fundamentalmente sobre o conceito de real, que ele havia começado a precisar no seminário sobre os quatro conceitos, de 1964 (Lacan, 1979). E, na seqüência, especialmente nos seminários de 1973-74 (RSI) e de 1975-76 (O Sinthoma), ao resgatar a referência plural aos nomes do pai que anunciara em seu seminário interrompido de 1963, Lacan forja as ferramentas conceituais com que a clínica lacaniana pode ultrapassar a normopatia da ordem fálica (Poli, 2005). O Édipo, então, do qual se serve o neurótico - ponto central da crítica de Deleuze e Guattari - é definido como um modo, entre outros, de amarração dos três registros do real, imaginário e simbólico. Abre-se, assim, a possibilidade de que outros modos de amarração criem respostas possíveis à existência, fora da norma fálica - outros modos como o delírio, mas também a criação artística, a produção de teoria, alguma forma própria de se fazer um nome com o qual se apresentar ao mundo e conduzir-se na vida, o que vai mostrar-se fundamental em especial na clínica com a psicose.

Guattari, por sua vez, militante de esquerda e psicanalista, parceiro de Jean Oury na Clínica La Borde, desde o início acompanha os seminários de Lacan em Saint Anne e se faz analisar por ele até 1960. Os ensaios que ele escreve, no início dos anos 60, trazem a marca dessa formação, através do uso de termos como sujeito, significante, fantasma de grupo, estrutura, mesmo quando formula noções novas, como o conceito de transversalidade, que ele contrapõe ao conceito de transferência no contexto da análise institucional. A aproximação de Lacan a Althusser, em 1964, precipita a ruptura de Guattari com o movimento lacaniano, levado, pela via do estruturalismo, ao que Guattari entende ser um excessivo formalismo e matematização. Mas, surpreendentemente, e apesar da repercussão e escândalo que a publicação de $O$ Anti-Édipo gera, Guattari mantém-se filiado à Escola Freudiana de Paris, pagando regularmente suas mensalidades, até a dissolução da mesma nos anos 80 (Roudinesco, 1988).

Já Deleuze, filósofo, era leitor atento de Lacan desde antes de seu encontro com Guattari. Em 1967, ele escreve um pequeno texto - "Em que se pode reconhecer o estruturalismo?" -, incluído na História da Filosofia de Chatelet (David-Menard, 2005), em que, numa leitura singular, presta sua homenagem ao estruturalismo em voga na França no início dos anos sessenta. No mesmo ano, publica Présentation de Sacher Masoch (Deleuze, 1973), edição revisada de um ensaio de 1961, em que recusa a interpretação corrente que une sadismo e masoquismo, destacando a especificidade do masoquismo como exercício de suspensão do prazer para sustentação do desejo. $\mathrm{O}$ estatuto particular que ele confere ao masoquismo tem como pano de fundo um questionamento das noções de prazer em Freud e de desejo em Lacan.

Em 1968, Deleuze $(1988,2006)$ publica Diferença e repetição, obra filosófica que ele diz articular-se com tudo o que produziu a seguir, inclusive o que virá a escrever com Guattari. Apesar de sua crítica posterior ao tom excessivamente acadêmico desse trabalho, Diferença e repetição é de fato um marco no seu pensamento, onde apresenta uma concepção sobre o tempo, a memória, a morte que atravessa o conjunto da sua obra. Em particular, o segundo capítulo, intitulado "A repetição para si mesma", estabelece um diálogo bastante fecundo com a psicanálise de Freud e Lacan, em que a idéia de prazer como princípio é novamente debatida, juntamente com o conceito de pulsão de morte. Ao mesmo tempo em que pontua sua crítica a essas noções, Deleuze ressalta, de Lacan, o conceito de falo simbólico, aproximado ao de objeto virtual, e a concepção de repetição presente no seminário sobre a carta roubada. Em A lógica do sentido, de 1969, Deleuze (1974) retoma o seminário da carta roubada, nomeando o paradoxo que nele se apresenta - o fato de que a carta não está nunca onde a procuramos e, inversamente, nunca a encontramos onde está (ou seja, o fato de que ela falta em seu lugar) como "paradoxo de Lacan". 
A parceria estabelecida com Guattari leva Deleuze a se ocupar da crítica à psicanálise, em especial, para além dos seus conceitos, em seus desdobramentos clínico-políticos. Na seqüência de $O$ Anti-Édipo, torrencialmente crítico, Mil Platôs, publicado em 1980, é fundamentalmente propositivo, dedicado à criação ou aprofundamento de conceitos como o de corpo-semórgãos, rizoma, devir, multiplicidade. De um platô a outro, pode-se rastrear o debate com a psicanálise, o qual comparece, ora com maior ora com menor ênfase, seja como pano de fundo, seja no primeiro plano da cena.

E Deleuze sozinho, em textos posteriores a $\mathrm{Mil}$ Platôs, como os reunidos em Crítica e clínica, publicado em 1993, dá continuidade à interlocução com a psicanálise no campo mesmo da clínica. Em especial no texto "O que as crianças dizem", reportando-se ao caso do pequeno Hans, Deleuze (1997) contrapõe o método cartográfico por ele proposto ao método psicanalítico, que ele identifica ao método arqueológico: para Deleuze, em vez de interpretar os enunciados, trata-se de acompanhar os movimentos, os trajetos, o sentido não estando remetido a um passado, mas fazendo-se no próprio caminhar. Deixamos de lado as aproximações possíveis, por exemplo, com a noção de tempo em Lacan, a que o próprio Deleuze já se reportara em Diferença e repetição, ou com o texto sobre as construções em análise, de Freud. O que queremos destacar é que "O que as crianças dizem" retoma a crítica à edipianização da psicanálise, mais de vinte anos depois de $O$ Anti-Édipo, dando mostras de que o debate não fôra encerrado.

Ainda que os que se inspiram na leitura de Deleuze e Guattari julguem que a partir de Mil Platôs os autores tenham se distanciado o suficiente da psicanálise para poder prescindir dela, inventando conceitos que desembocam numa outra concepção de clínica, no limiar entre a filosofia, a arte e a política, sustentamos que é desde uma interlocução privilegiada com a psicanálise que se forja o seu pensamento. Se essa interlocução enuncia, por um lado, uma total recusa do conceito de desejo atrelado ao Édipo e à castração, ela indica, por outro, que a formulação de noções como as de inconsciente maquínico, corpo-sem-órgãos e máquinas desejantes nutre-se de conceitos freudianos como os de pulsão, inconsciente e sexualidade perverso polimorfa. O Anti-Édipo, e o que dele decorre, não é, por princípio, uma anti-psicanálise. Antes, pode servir-nos de instrumental para uma avaliação dos limites e possibilidades da psicanálise no contemporâneo (Néri, 2003).

Contudo, Lacan não discorre sobre Deleuze e Guattari da mesma forma que estes se referem a ele ou a Freud. Como já dissemos, não há, nos escritos e seminários de Lacan, referências explícitas ao texto desses dois expoentes da crítica à psicanálise. Porém, apesar de não enunciadas por Lacan, acreditamos ser possível acompanhar as reverberações do que escrevem Deleuze e Guattari no texto lacaniano e vice-versa. A confrontação mais detida do texto de um ao texto dos outros, como escritas que se falam, é objeto da pesquisa que temos pela frente. Os 36 anos que nos separam do momento capital dessa conversa textual, que foi a publicação d'O Anti-Édipo, talvez permitam escutar de outra forma o que se dizem Lacan, Deleuze e Guattari, sem os ruídos que o anedotário em torno ao seu acontecimento faz ecoar.

Em O que é a filosofia, Deleuze e Guattari (2004) tomam ao Amigo como personagem conceitual da filosofia, como presença intrínseca ao pensamento que manifesta uma relação vital ao Outro, condição de possibilidade daquilo que é próprio à atividade filosófica: a criação de conceitos. O amigo da sabedoria é o que a ela aspira, almeja, o que comporta tanto tensão amorosa em direção do objeto do desejo quanto desconfiança competitiva em relação ao rival - eis aí o agôn, característico das cidades gregas e constitutivo das relações de amizade.

É nessa perspectiva que se instaura nosso campo de investigação. Nos percursos que vão e vêm, da escrita de Deleuze e Guattari à escrita e aos seminários de Lacan, buscamos aquilo que pode ser lido como o genuíno exercício de uma amizade, que carrega a potência da criação de conceitos. As formulações de Derrida (1998) e Foucault $(1994,2004)$ acerca do tema da amizade esclarecem-nos a esse respeito e servem de guia metodológico: não se trata da amizade vivida na esfera da intimidade e das identificações, que iguala o amigo ao irmão, ao semelhante, espelho da alma do outro, mas, ao contrário, a amizade como diferença, distância, assimetria, numa agonística que, pondo em questão certezas e crenças, faz deslocar o pensamento e inventa formas não prescritas à existência. ${ }^{1}$ Nietzsche (1883/1999), em Assim falou Zaratustra, descreve o amigo como um terceiro entre eu e mim que me incita à transformação. É o que nos move a ler Deleuze e Guattari como amigos de Lacan.

\section{Notas}

1 Cf. Francisco Ortega (2000, p.114), no segundo volume de sua trilogia sobre a amizade:

Trata-se, antes, de levar a sério a incomensurabilidade existente entre o eu e o outro, o que impede sua incorporação narcisista. Em outras palavras, não utilizarmos o amigo para fortalecer nossa identidade, nossas crenças, isto é, "o que somos", mas a possibilidade de concebermos a amizade como um processo, no qual os indivíduos implicados trabalham na sua transformação, na sua invenção. Diante de uma sociedade que nos instiga a saber quem somos, a descobrir a verdade sobre nós mesmos, e que nos impõe uma determinada sub- 
jetividade, esse cultivo da distância na amizade levaria a substituir a descoberta de si pela invenção de si, pela criação de infinitas formas de existência.

\section{Referências Bibliográficas}

David-Ménard, M. (2005). Deleuze et la psychanalyse. L'Altercation. Paris: PUF.

Deleuze, G. (1973). Sade / Masoch. Lisboa: Assírio \& Alvim. (Trabalho original publicado em 1967, título original: Preséntation de Sacher-Masoch).

Deleuze, G. (1974). Lógica do sentido. São Paulo: Perspectiva. (Trabalho original publicado em 1969).

Deleuze, G. (1988). Diferença e repetição. Rio de Janeiro: Graal. (Trabalho original publicado em 1968).

Deleuze, G. (1992). Entrevista sobre $O$ anti-Édipo (com Félix Guattari). In G. Deleuze, Conversações (pp.23-36). Rio de Janeiro: 34 (Trabalho original publicado em 1972).

Deleuze, G. (1997). Crítica e clínica.. São Paulo: 34. (Trabalho original publicado em 1993).

Deleuze, G. (1996). Meu próximo livro vai chamar-se Grandeza de Marx. Depoimento a Didier Eribon. Cadernos de subjetividade: Gilles Deleuze, 4(especial), pp. 26-30.

Deleuze, G. (2006). Diferença e repetição (2a. ed. rev. e atual). Rio de Janeiro: Graal. (Trabalho original publicado em 1968).

Deleuze, G. \& Guattari, F. (1976). O Anti-Édipo. Capitalismo e esquizofrenia. Rio de Janeiro: Imago. (Trabalho original publicado em 1972).

Deleuze, G. \& Guattari, F. (1995). Mil platôs. Capitalismo e esquizofrenia (Vol. 4). São Paulo: 34. (Trabalho original publicado em 1980).

Deleuze, G. \& Guattari, F. (1996). Mil platôs. Capitalismo e esquizofrenia. (Vol. 3). São Paulo: 34. (Trabalho original publicado em 1980).

Deleuze, G. \& Guattari, F. (1997). Mil platôs. Capitalismo e esquizofrenia. (Vol. 5). São Paulo: 34. (Trabalho original publicado em 1980).

Deleuze, G. \& Guattari, F. (2004). O que é a filosofia (2 ed.). São Paulo: 34. (Trabalho original publicado em 1991).

Derrida, J. (1998). Políticas de la amistad (seguido de El oído de Heidegger). Madri: Editorial Trotta (pp.11-338). (Trabalho original publicado em 1994).

Foucault, M. (1981). Da amizade como modo de vida. Entrevista de Michel Foucault a R. de Ceccaty, J. Danet e J. le Bitoux, publicada no Jornal Gai Pied, no 25 , abril de 1981, pp. 38-39 (W. F. Nascimento, trad.). (Trabalho original publicado em 1981). Acesso em 25 de novembro, 2005, em $<$ http://www. unb.br/fe/tef/filoesco/foucault/amitie.html>

Foucault, M. (2004). Michel Foucault, uma entrevista: sexo, poder e a política da identidade. Entrevista com B. Gallagher eA. Wilson. Verve, 5, pp. 260-277. (Trabalho original publicado em 1984). Acesso em 23 de dezembro, 2006, em

$<$ http://www.nu-sol.org/verve/n5/verve5-2004.pdf $>$.

Gandillac, M. (2005). Vers une schizo-analyse. In Gilles Deleuze [Coleção Arc/Inculte] (pp.145-156). Paris: Inculte. (Trabalho original publicado em 1972).

Lacan, J. (1979). O seminário, Livro 11: Os quatro conceitos fundamentais da psicanálise. Rio de Janeiro: Zahar. (Trabalho original publicado em 1973).
Lacan, J. (1992). O seminário, Livro 17: O avesso da psicanálise. Rio de Janeiro: Zahar.

Lacan, J. (1985). O seminário, Livro 20: Mais, ainda. Rio de Janeiro: Zahar. (Trabalho original publicado em 1975).

Lacan, J. (s.d.) O seminário: R.S.I. 1974-1975. Tradução mimeografada.

Lacan, J. (2007) O sintoma. 1975-1976. Rio de Janeiro: Zahar.

Lacan, J. (2005). Nomes-do-pai. Rio de Janeiro: Zahar. (Seminário proferido em 20 de novembro de 1963).

Ortega, F. (2000). Para uma politica da amizade: Arendt, Derrida, Foucault. [Coleção Conexões]. Rio de Janeiro: Relume-Dumará.

Neri, R. (2003). Anti-Édipo / Psicanálise: um debate atual. Ágora - Estudos em Teoria Psicanalítica, 6(1), pp. 21-43. Acesso em 11 de fevereiro, 2007, em

$<$ http://www.scielo.br/scielo.php?pid=S $1516-$ $14982003000100002 \&$ script $=$ sci_arttext\&tlng=en $>$.

Nietzsche, F. (1999). Assim falou Zaratustra (P. Nassetti, trad.). São Paulo: Martin Claret. (Original publicado em 1883).

Palombini, A. L. (2007). Vertigens de uma psicanálise a céu aberto: a cidade. Contribuições do acompanhamento terapêutico à clínica na reforma psiquiátrica. Tese de Doutorado, Programa de Pós-Graduação em Saúde Coletiva, Universidade Estadual do Rio de Janeiro. Rio de Janeiro. Acesso em 20 de agosto, 2007, em http://bases.bireme.br/ cgi-bin/wxislind.exe/iah/online/?IsisScript $=$ iah/iah.xis\&src $=$ google \&base $=$ LILACS\&lang $=$ p\&nextAction $=$ lnk\&exprS earch=449190\&indexSearch=ID.

Poli, M. C. (2005). Clínica da exclusão. São Paulo: Casa do Psicólogo.

Rolnik, S. (2006). Entrevista a Suely Rolnik. Acesso em 25 de junho, 2007, em http://www.oestrangeiro.net/index2. php?option=com_content\&do_pdf=1\&id=110. Roudinesco, E. (1988). História da psicanálise na França. A batalha dos cem anos. 1925-1985. (Vol. 2). Rio de Janeiro: Zahar.

Warat, L.A. (1992). Vida e obra de Félix Guattari. É difícil dizer adeus: do anti-édipo à ecosofia. Revista Seqüência. Estudos jurídicos e políticos, 13(25), pp. 47-50. Acesso em 25 de junho, 2007, em http:/www.buscalegis.ufsc.br/arquivos/ Seq25Warat-VidaOFG.pdf.

Analice de Lima Palombini é Docente do Departamento de Psicanálise e Psicopatologia do Instituto de Psicologia da Universidade Federal do Rio Grande do Sul, mestre em Filosofia pela mesma universidade, doutora em Saúde

Coletiva pelo Instituto de Medicina Social da UERJ.

Endereço para correspondência: Av. Jerônimo de Ornelas 651/11 - Bairro Santana. Porto Alegre / RS. CEP 90040-341 E-mail: analicepalombini@uol.com.br

Lacan, Deleuze e Guattari: escritas que se falam

Analice de Lima Palombini

Recebido em: 02/04/2008

Aceito em: 24/09/2008 